\title{
Character Strengths and Deep Connections Following Hurricanes Katrina and Rita: Spiritual and Secular Pathways to Resistance Among Volunteers
}

\author{
AMY L. AI \\ College of Social Work \\ Florida State University \\ ROSLYN RICHARDSON \\ Department of Social Work \\ Southern University and A\&M College \\ CAROL PlUMMER \\ School of Social Work \\ University of Hawai' i at Manoa \\ Christopher G. Ellison \\ Department of Sociology \\ University of Texas at San Antonio
}

\author{
CATHERINE LeMiEUX \\ School of Social Work \\ Louisiana State University
}

TERRENCE N. TICE

Department of Philosophy

University of Michigan

\author{
BU HUANG \\ Bastyr University Research Institute \\ Bastyr University
}

\begin{abstract}
This study investigated a conceptual model with two pathways, altruism and perceived spiritual support, leading to resilience among student volunteers following Hurricanes Katrina and Rita $(H-K R)$. Both strengths share the sense of deep connections. Parallel pathways with the two major constructs were estimated using structural equation modeling, adjusting for demographics and peritraumatic emotional reactions. The two indicators may have served as a protective mechanism for all volunteers despite differing racial/cultural backgrounds. The potential protection of these strength factors was mediated through optimism and hope. Resilience among minority volunteers was associated more with faith-related strengths, as indicated in the relevant pathway that also contributed to their altruistic actions. The resilience of white volunteers, however, was directly associated with altruism, a strength that does depend heavily on religious beliefs. Further, the modification index suggested a direct path from race to depression.
\end{abstract}

Keywords: spirituality, optimism, hope, positive psychology, hurricanes, volunteers, resilience, altruism, perceived spiritual support.

\section{INTRODUCTION}

In the fall of 2005, Hurricanes Katrina and Rita (hereinafter H-KR) wrought an unprecedented catastrophe upon the entire Gulf Coast, followed by massive relocation of victimized populations in the Deep South of the United States. In the midst of intensified needs, local minority and white student volunteers - some of whom were themselves evacuated from areas affected by H-KR-worked together to provide social services for evacuees (Plummer et al. 2008). Massive disasters like H-KR may illuminate the claim that "the role of crisis [acts] as a possible crucible for what is best about people" (Peterson and Seligman 2003). However, a question remains: 
Figure 1

Basic conceptual model with concept structure (Model 1)

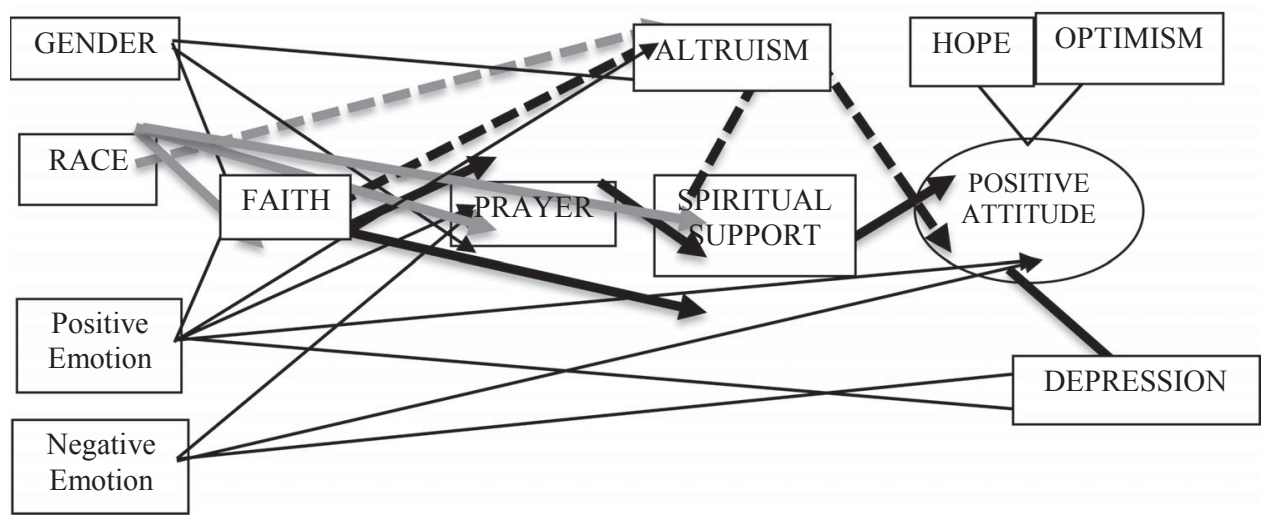

Note: The circled construct means a latent factor and squared constructs refer to measurable indicators, to use SEM terms. For example, in this SEM altruism is an indicator for a latent factor, character strength kindness, which undersubsumes a virtue, humanity. Because there is one indicator for kindness as described in the text, only the indictor is shown to save space. The same is true for perceived spiritual support, an indicator for a latent factor, character strength spirituality.

How could volunteers rise above personal and communal tragedies while remaining personally resilient in face of adversity? Compared with rapid recovery after a crisis, resilience often refers to the capacity for bouncing back after trauma, including employing adaptive coping strategies (Masten 2001) or positive emotions (Tugade, Fredrickson, and Barrett 2004) to cope in the face of adversity; achieving good outcomes in spite of serious threat (Masten 2001); maintaining a stable equilibrium (Bonanno 2004); or avoiding psychopathology (Tugade, Fredrickson, and Barrett 2004). The latter perspective seems to reflect a more narrowly defined but measurable concept, indicated by low levels of psychological symptoms (e.g., depression). This view has been used to conceptualize one aspect of resilience following trauma (King et al. 1999; McFarlane and Yehuda 1996). We used depression as one indicator for the latent factor resilience in this study.

Hope and optimism are indicators of the character strength hope in positive psychology (Peterson and Seligman 2004). Linking two distinct literatures that address human strength (positive psychology and psychology of religion and spirituality), the present study evaluated how two spiritual and secular character strengths, spirituality and kindness, could enhance hope, which, in turn, mitigated depression (as an indicator of low resilience). Spirituality and kindness reflect two levels of deep human connections. A 9/11 modeling study demonstrated that hope mediated the indirect effect of spiritual support on mental health and on posttraumatic growth (Ai et al. 2005; Ai, Tice et al. 2011). Previous research also has defined deep connections as the sense of profound relation with a significant entity or context in life that bestows grand purpose and meaning to the individual, based on various worldviews (Ai and McCormick 2010; Ai, Tice, and Kelsey 2009; Dilthey 1991). To demonstrate such strength pathways leading to resilience among H-KR volunteers, we evaluated a hypothetical structural equation model (SEM, Model 1, Figure 1). As will be apparent (Model 1), bold paths present core ideas to be estimated, with black bold paths indicating certain commonalities between both minority and white respondents, based on the finding from responses to another collective trauma-the September 11, 2001, attacks (Ai et al. 2005; Ai, Tice et al. 2011) — and gray bold paths indicating faith-related between-subgroup differences.

It should be noted that the $9 / 11$ study did not show a direct effect of religious factors, but instead demonstrated an indirect effect of using prayer for coping on better resilience, 
mediated by a spiritual support/optimistic expectations path (Ai et al. 2005; Ai, Tice et al. 2011). In the current study, spiritual pathways around spiritual support (black bold lines, Figure 1, Model 1) replicated similar links in the $9 / 11$ models, whereas more secular pathways around altruism (black bold dashes) were designed specifically to reflect the context for this H-KR model. Below, we elaborate on constructs in this model to justify parallel pathways, manifesting two levels of human connections, and on differential faith effects on strength-based paths. We recruited over 500 minority and white respondents (94 percent of whom volunteered in the three months after H-KR) when their universities in areas affected by H-KR (Jackson State University, Louisiana State University, Southern A\&M University, the University of Alabama, and the University of Houston) were heavily engaged in disaster relief. Reflecting deep connections in the two-dimensional reality, Model 1 assumed that both character-strength constructs would contribute to resilience among all volunteers, mediated through optimism and hope. Based on the literature, gender, race, and peritraumatic emotional responses were included in the model (Ai et al. 2005). From gender and race, pathways directed to faith-based factors (gray bold lines, Figure 1, Model 1) replicated similar links in the $9 / 11$ models, whereas secular pathways directed to altruism (gray bold dashes) were designed to reflect the particular context for our H-KR model. We were also curious about the commonality and uniqueness of minority and white subgroups.

\section{Deep Connections, Well-Being, and the Mediation of Hope: Commonality}

In Model 1 (Figure 1), paths from spirituality and kindness to resilience, as indicated by low levels of depression, present the commonality between minority and white respondents, specifically reflecting their shared experiences in volunteering and coping with H-KR. Frankl (1959:85) posited that trauma survivors need both meaningful relations and meaningful actions when confronted with severe threats that may transcend suffering or despair through a renewed sense of deep connection. Buber ([1923] 1958) described human relations as a triad of society, spirit, and nature, all of which may involve deep interplays between humans and objects in the perceived reality. This triad may be divided into two dimensions of connections corresponding (in positive psychology terms) to physical and nonphysical dimensions of life, which corresponds roughly to spiritual and secular aspects of life. A primary connection concerns a link with other beings in nature and society, the physical reality that is shared by all humans. A secondary connection is tied to spirit, the nonphysical reality (e.g., God) diversely conceptualized by different cultures. A sense of deep connection, whether in the spiritual or secular aspects of life, could convey meaning for human existence, a motivating force for life, and help for individuals' survival in crisis situations (Ai, Tice, and Kelsey 2009).

Indeed, human interplay with other beings in the physical reality may forge a sense of natural interdependence between an individual and the world at large (see Spinoza 2000). A religious connection perceived in the nonphysical reality may foster a sense of spiritual dependence on God (Schleiermacher [1821] 1969) or integration with other forces (e.g., ancestor spirits, Buddhahood). As shown in Model 1, perceived spiritual support and altruism are indicators of spirituality and kindness. Each may primarily feature characteristics of nonphysical or physical dimensions in deep connections concerning the perceived reality, but typically not both. Other strengths (e.g., gratitude and universal love), however, may be devoted to gods and humans alike. In positive psychology, spirituality and kindness are subsumed under two overarching virtues, transcendence and humanity, respectively (see Peterson and Seligman 2004:29-30). Both strength concepts are meaning-laden and may involve goal-oriented meaningful actions, engagement in which can promote well-being (Seligman et al. 2005). Accepting the universality of human virtues and character strengths in relation to both levels of human reality, positive psychologists derived their categories from the world's seven influential legacies, involving all major faiths and cultural 
traditions (Peterson and Seligman 2004). Accordingly, in the present study we also assumed that both minorities and white respondents should share such commonalities.

Likewise, in either dimension above, deep connections that humans have with the larger world can open their minds to the broad horizon of new possibilities (Vieten 2006) or to such character strengths as hope (see Marcel 1995) and optimism (see Peterson 2000). Concerning spiritual connections, the promised hope is delineated throughout the New Testament (Ai et al. 2004) and the Old Testament. For example: "I know the plans I have for you, declares the Lord, ... plans to give you the hope and a future" (Jeremiah 29:11,13). However, optimism, a concept similar to hope in positive psychology, is more secular in nature, emerging only since the French Revolution. Concerning interpersonal connections, Post's (2005) review of research on altruistic love and behaviors suggested benefits for altruists to remain positive despite encountering risk in undertaking self-sacrificing actions. While ample evidence has linked positive attitudes to outcomes (Peterson 2000; Seligman et al. 2005), only a handful of empirical studies have modeled the mediation of such expectations in the pathway of spirituality to resilience (Ai et al. 2007; Ai, Tice et al. 2011; Idler and Kasl 1997a, 1997b; Krause 2002). Even less research has used statistical modeling to test its mediation in the altruism effect following a collective trauma. Investigating the role of deep connection-based strengths in resilience after $\mathrm{H}-\mathrm{KR}$ through this positive mediation will help fill the existing gap in the literature and expand the 9/11 model (Ai et al. 2005; Ai, Tice et al. 2011) in the context of disaster-related collective trauma.

\section{Spiritual Support, Leading to Resilience with a Religious Root Historically}

Centering on spiritual pathways in Model 1, perceived spiritual support, indicating spirituality, can demonstrate a nonphysical deep connection as a potential coping resource for resilience (Emmons 2000; Peterson 2000). Such support was defined as the perceived intrapersonal support derived from "a deep connection with a higher power or a spiritual relationship in a faith, which encompasses intimacy, emotional, cognitive, and resource aspects of this relation" (Ai et al. 2005). Marcel (1995) asserted that ontological existence is a need and a demand for understanding one's role in the cosmos. In psychology of religion, such connection is considered to be at the core of spirituality, seen as the search for the sacred and a key to coping with adversity (Pargament 1997). In positive psychologists' view, spirituality paves a way to relationships with the sacred, transcendence, and capacity to engage in virtuous behavior (Emmons 2000); religion promotes a future orientation by instilling meaning, enlightenment, and aspiration (Peterson 2000). Expanding Maton's (1989) early work, the 9/11 study developed a 12-item scale to reflect four interrelated components of perceived spiritual support: (1) intimacy, (2) emotional support, (3) cognitive guidance, and (4) spiritual resources (Ai et al. 2005). Empirical research has shown that perceived spiritual support, though viewed as being "vicarious" in psychology, can function in a protective manner similar to support from social networks (Ai, Tice et al. 2011; Koenig 1994), and that it may serve as a protector among humans encountering sudden and unexpected traumatic events (Pargament 1990; Spilka and Schmidt 1983).

Despite the assumed commonality in character strengths among subgroups, paths from faith and race to spiritual support and altruism presented in Model 1 are derived from different cultural roots, dating back to influential intergenerational legacies. In general, minorities in the United States tend to rely on faith to cope with adversities (Ai et al. 2005; Ai, Tice et al. 2011; Krause 2002; Levin, Taylor, and Chatters 1994). In particular, faith-related paths were relevant to the Deep South culture of African Americans who constituted half of our sample. African-American spirituality historically has embraced a sense of spiritual connection forged by communal struggle against poverty, social oppression, and racism (Smith 1999). Faith is a meaningful, empowering, and resource-laden dimension of African-American life that constitutes 
a significant factor in the ability of black people to cope (Chatters and Taylor 1989). Previous research has found that intrinsic religiosity was inversely related to total distress and depression among African Americans (Lesniak et al. 2006). Also, the relationship between African-American use of spiritual coping and resilience benefits has been reported in survey research using national (Taylor, Chatters, and Levin 2004), regional (Dilworth-Anderson, Boswell, and Cohen 2007; Lawson and Thomas 2007; Tarakeshwar et al. 2005), and student (Constantine et al. 2002) samples.

Previous work with the present sample also shows cultural differences between people who identify as black or white in terms of attributions of inadequate responses to H-KR, controlling for disaster factors and strength of faith (Ai, Plummer, Hoe et al. 2011). Also, symptoms of posttraumatic stress in white respondents were affected by previous trauma, whereas the same symptoms in black respondents were more linked with current stressors and hopelessness (Ai, Plummer, Kanno et al. 2011). Although black respondents reported higher levels of faith strengths, this culturally relevant factor had no direct effect on either outcome. Accordingly, we wondered whether culturally embraced belief differences could have indirect effects on resilience, mediated via pathways of shared strengths, similar to findings from a 9/11 study (Ai, Tice et al. 2011). Accordingly, we expected stronger direct or indirect effects of minority race/ethnicity than white race on all faith factors in Model 1.

\section{Altruism Leading to Resilience with a Different Root in Recent History}

Centering on secular pathways in Model 1, altruism, indicating kindness, can demonstrate a deep physical connection in caring about others as a potential source of personal resilience. Altruism is a universal aspect of human morality, while altruistic emotion or behaviors consist of personal benevolence, unselfish concern for the welfare of others, and giving without regard for reward or recognition (Monroe 1996; Post 2005). Participants engaged in altruistic actions in Monroe's (1996) study viewed the world from a community-oriented perspective and considered themselves not heroes, but people tied with others through a common humanity. If one perceives humanity in light of deep connections with fellow humans, then altruism in crisis would fulfill one's higher moral consciousness and provide personal satisfaction. Altruistic acts have been associated with a reduced sense of depression (Musick and Wilson 2003), happiness and wellness (Post 2005; Schwartz et al. 2003), general well-being in younger adults (Krueger, Hicks, and McGue 2001), and greater self-worth (Sullivan and Sullivan 1997). A study of Vietnam-era combat veterans singled out altruism as the most influential predictor of protection against posttraumatic stress disorders (Kishon-Barash, Midlarsky, and Johnson 1999).

Monroe (1996) and other scholars have identified the cultural root of altruism. No doubt, this character is a universal human strength based on internalized social norms that give meaning to action, as do other value-based moral cognitions. Entrenched in an ancient Greek and Christian concept, agape (universal love), altruism has long been considered a religious virtue (Grant 2001:168-89). It was perceived as a cardinal virtue in the Confucian ethics of ancient China as well. Nevertheless, in recent Western history it was the French atheist Comte who coined the term altruisme to distinguish benevolence from egoism, both of which are forms of human motivation. In contrast with self-serving egoism, Comte posited that altruism is an unselfish desire to "live for others" and that promoting universal altruism would serve the common goals of happiness and progress ([1851-1875] 2012:556; see also Dixon 2005). The concept of altruism later was adopted by the British and was prominent in Victorian-era discourses on the interplay between science and religion. For the Victorian British, altruism represented an aspiring humanistic religion (or spirituality, in modern terms) to atheists (Dixon 2005). With this cultural root in mind, we expected 
a strong direct effect of white race related to less religiousness (Ai et al. 2005) on altruism as a secular spiritual strength pathway to resilience.

\section{The Present Study}

We tested a hypothetical model to evaluate the parallel spiritual and secular pathways (spiritual support and altruism) to resilience, both mediated through positive attitudes (or optimistic expectations) as indicated by hope and optimism, despite cultural differences between minorities and white respondents (thick lines and dashes, Model 1). Based on Monroe's (1996) argument about worldview effects and Post's (2005) articulation of the link between faith and altruism, we anticipated that faith factors might also contribute to altruism. While female gender has been associated with faith-based coping (Levin, Taylor, and Chatters 1994), findings on the genderaltruism link have been mixed (Andreoni and Vesterlund 2001; Belansky and Boggiano 1994; Monk-Turner et al. 2002). We therefore tested the potential role of gender in both pathways. Finally, to ensure that the major constructs tested were contextually relevant, we controlled for negative and positive peritraumatic emotional reactions to H-KR (meaning reactions right after the disasters) as indicators of initial reaction, as was done in the 9/11 models (Ai et al. 2005). Likewise, we assumed opposite effects of these two emotional reactions on resilience.

It is worth noting that in our hypothetical model (Model 1, Figure 1) neither faith nor prayer was directly associated with positive attitudes based on the SEM findings in a 9/11 study (Ai et al. 2005), but spiritual support was associated with positive attitudes. A question may arise about how spiritual support differs from faith and prayer. Whereas all three of these measures may manifest as a believer's connection with God or a spiritual force, they represent three distinct aspects of this deep relationship. Faith, as assessed in the 9/11 study and in the current analyses, is about worldviews, indicating the importance of various religions and degree of spiritual orientation (Ai et al. 2005; Chatters, Levin, and Taylor 1992). The Private Prayer Scale was developed to assess the coping processes, employing religious actions or strategies during a time of distress (Ai et al. $2002,2005)$. Although a person can have a strong faith, be it religious or not, he or she might not employ prayer for coping or facing distress. On the other hand, the Perceived Spiritual Support Scale was designed to assess an outcome in relation to faith, namely, the believer's perception of the extent to which one's spiritual faith or religious figure has offered support (e.g., comfort, love, strength, survival) up to the time of assessment (Ai et al. 2005, 2012). In distress, a person can use prayer as a coping action with or without perceiving expected outcomes relevant to one's faith. Accordingly, the three variables were not presented as three indicators for one latent factor in Model 1 (see Figure 1).

\section{Method}

\section{Procedure}

Minority and white volunteers were recruited from five professional schools that train mental health professionals (e.g., social workers) at five universities (see Plummer et al. 2008 for further description). Currently enrolled students who were engaged in disaster relief actions in the wake of H-KR, when their schools were actively participating, were eligible to participate in the study. Researchers from each site distributed a package containing an informed consent letter, consent form, survey instrument, and a return envelope, approved by the Institutional Review Boards (IRB) of the five universities involved. Posters, emails, and direct faculty contact were used to encourage participation. The questionnaire, requiring approximately 30 minutes to be completed, included major constructs in the hypothetical model, as well as measures of H-KR-related stressors and demographics. 


\section{Respondents}

The vast majority of the sample had voluntarily engaged in H-KR-related disaster relief work, including donating services, offering their homes to others, providing counseling, and working in shelters for victims (Plummer et al. 2008) as part of the collective efforts of their schools. Among 554 participants, 9 percent were transferred from institutions in areas directly impacted by H-KR (e.g., New Orleans). The initial analysis showed no effect of university sites on the outcome of major interest; thus, the sample was combined for modeling purposes. The largest subgroups were African American (54 percent) and non-Hispanic white (37.2 percent), followed by Hispanics (3.2 percent), others (2.2 percent), Asian/Pacific Islanders (1.6 percent), multiracial (.9 percent), those missing race data (.5 percent), and Native Americans (.4 percent). The majority of the combined sample was female ( 88 percent). The mean age was 28.9 years $(S D=9.6)$. The age and gender distributions were comparable to those of the student populations at five mental-health-related professional schools in the disaster area.

\section{Measures}

There was a three-month time lapse between the disaster and the onset of the study primarily because of the time needed to gain IRB clearance and prepare instrumentation at the five involved sites. Therefore, certain constructs concerning the immediate reaction to H-KR had to be assessed somewhat retrospectively. These included, in particular, using prayer for coping and peritraumatic emotional responses, referring to the context of H-KR disasters for these measures in order to distinguish disaster as a specific reason for prayer use, ranging from prayers as emotional reactions to the disaster to prayer in normal usage. Peritraumatic refers to reactions at the time and immediately following the disasters. All constructs used in the SEM are presented in Table 1.

\section{Depression}

As an indicator of outcome resilience, depression was measured with the widely used 20item Center for Epidemiological Studies-Depression Scale (CES-D) (Radloff 1977). Participants stated how often they had experienced each symptom during the previous week. In this study, Cronbach's alpha $(\alpha)$ for the CES-D was $.90(M=16.28, S D=10.78)$.

\section{Positive Attitudes}

Positive attitudes, or character strength hope, consisted of two indicators, hope and optimism, measured with the Hope Scale (Snyder et al. 1991) $(\alpha=.85, M=32.88, S D=4.38)$ and the Life Orientation Test (Scheier and Carver 1985, 1987) $(\alpha=.76, M=22.21, S D=4.93)$, with eight items each. In each case, participants stated how they felt about each item during the past month.

\section{Altruism}

As an indicator of character strength kindness, altruism was measured with the 20-item Self-Report Altruism Scale (Rushton, Chrisjohn, and Fekken 1981), which assesses the extent to which respondents had engaged in different types of altruistic behaviors or actions (e.g., giving money to charity, donating blood, volunteering). Participants responded on a four-point scale $(0=$ never, $4=$ very often $)$ concerning each statement $(\alpha=.91, M=47.91, S D=15.41)$.

\section{Spiritual Support}

As an indicator of character strength spirituality, spiritual support was measured with the 12-item Spiritual Support Scale (Ai et al. 2005), assessing spiritual relationships in diverse beliefs (e.g., "I have been inspired by my religious or spiritual faith in the face of distress"). In addition, respondents specified the spiritual higher powers in their faiths, answered with a list of 10 choices and an additional "other" item. Participants responded on a four-point scale 
Table 1: Intended prayer for coping and major constructs

\begin{tabular}{|c|c|c|c|}
\hline Target of prayer used for after $\mathrm{H}-\mathrm{KR}$ & $\begin{array}{c}\text { Minority } \\
N(\%)\end{array}$ & $\begin{array}{l}\text { White } \\
N(\%)\end{array}$ & $\chi^{2}$ \\
\hline \multirow[t]{2}{*}{ Souls of victims } & 242 & 90 & \\
\hline & $(69.9 \%)$ & $(44.1 \%)$ & $<.001$ \\
\hline \multirow[t]{2}{*}{ Families } & 317 & 164 & \\
\hline & $(91.4 \%)$ & $(80.0 \%)$ & $<.001$ \\
\hline \multirow[t]{2}{*}{ Safety of yourself } & 320 & 146 & \\
\hline & $(92.2 \%)$ & $(71.2 \%)$ & $<.001$ \\
\hline \multirow[t]{2}{*}{ Evacuees } & 322 & 159 & \\
\hline & $(92.8 \%)$ & $(77.6 \%)$ & $<.001$ \\
\hline \multirow[t]{2}{*}{ Coping strength } & 261 & 77 & \\
\hline & $(75.2 \%)$ & $(37.6 \%)$ & $<.001$ \\
\hline \multirow[t]{2}{*}{ Those missing loved ones } & 311 & 134 & \\
\hline & $(89.6 \%)$ & $(65.4 \%)$ & $<.001$ \\
\hline \multirow[t]{2}{*}{ Those living in shelters } & 307 & 148 & \\
\hline & $(88.5 \%)$ & $(72.2 \%)$ & $<.001$ \\
\hline \multirow[t]{2}{*}{ Responders } & 260 & 137 & \\
\hline & $(74.9 \%)$ & $(66.8 \%)$ & $<.050$ \\
\hline \multirow[t]{2}{*}{ Never happen again } & 212 & 54 & \\
\hline & $(61.1 \%)$ & $(26.3 \%)$ & $<.001$ \\
\hline \multirow[t]{2}{*}{ Strength to be helpful } & 283 & 127 & \\
\hline & $(81.6 \%)$ & $(62.0 \%)$ & $<.001$ \\
\hline \multirow[t]{2}{*}{ Best thing } & 260 & 96 & \\
\hline & $(74.9 \%)$ & $(46.8 \%)$ & $<.001$ \\
\hline \multirow[t]{2}{*}{ God's will } & 285 & 105 & \\
\hline & $(82.1 \%)$ & $(51.2 \%)$ & $<.001$ \\
\hline \multirow[t]{2}{*}{ Other prayer } & 135 & 48 & \\
\hline & $(40.5 \%)$ & $(26.5 \%)$ & $<.010$ \\
\hline \multirow[t]{2}{*}{ Major constructs in the model } & Means (SDs) & Means (SDs) & $p$-value $(T)$ \\
\hline & 10.31 & 9.02 & \\
\hline Faith & $(1.59)$ & $(2.33)$ & $<.001$ \\
\hline \multirow[t]{2}{*}{ Prayer } & 14.00 & 11.97 & \\
\hline & $(2.51)$ & $(3.49)$ & $<.001$ \\
\hline \multirow[t]{2}{*}{ Spiritual support } & 43.19 & 36.97 & \\
\hline & $(7.03)$ & $(10.21)$ & $<.001$ \\
\hline \multirow[t]{2}{*}{ Altruism } & 46.72 & 49.92 & \\
\hline & $(15.31)$ & $(15.41)$ & $<.050$ \\
\hline \multirow[t]{2}{*}{ Optimism } & 22.41 & 21.86 & \\
\hline & $(4.89)$ & $(4.99)$ & ns \\
\hline \multirow[t]{2}{*}{ Hope } & 32.81 & 33.00 & \\
\hline & $(4.80)$ & $(3.56)$ & ns \\
\hline \multirow[t]{2}{*}{ Depression } & 16.98 & 15.11 & \\
\hline & (10.76) & (10.73) & $=.050$ \\
\hline \multirow{2}{*}{ Negative emotion } & 12.25 & 12.30 & \\
\hline & $(4.28)$ & $(3.59)$ & ns \\
\hline \multirow[t]{2}{*}{ Positive emotion } & 23.97 & 23.21 & \\
\hline & $(4.08)$ & $(3.95)$ & $<.050$ \\
\hline
\end{tabular}

Note: $N=554$. 
$(1=$ strongly disagree, $4=$ strongly agree $)$ concerning each statement during the time following $\mathrm{H}-\mathrm{KR}(\alpha=.97, M=40.88, S D=8.87)$.

\section{Using Prayer for Coping}

One indicator of worldview-based coping was measured with the Using Private Prayer as a Means for Coping Scale (Ai et al. 2002). The original three items included aspects of (a) belief in prayer's importance, (b) faith in its efficacy, and (c) use of it to cope. In the H-KR version, we included an additional item: (d) praying with others to cope with H-KR. The scale was initially designed for studies of traumatic medical events (Ai et al. 2002), so we modified the instructions for the current study to reflect the H-KR context. Participants responded on four-point scales $(1=$ strongly disagree, $4=$ strongly agree $)$ concerning each statement during the time following H-KR ( $\alpha=.82, M=13.25, S D=3.07)$. Respondents also completed a 12-item list of targets of prayer (plus an "other" item) as one reaction to H-KR, as presented in Table 2.

\section{Strength of Faith}

As one indicator of worldview, strength of faith was measured with three questions used in $\mathrm{Ai}$ and colleagues' (2005) 9/11 study, two about importance of religion drawn from the Three-Factor Religiosity Scale (Chatters, Levin, and Taylor 1992) and one about degree of spiritual orientation. Participants responded on a four-point scale $(1=$ not at all, $4=$ very much $)$ concerning each item $(\alpha=.76, M=9.83, S D=2.00)$.

\section{Peritraumatic Emotional Responses}

As one indicator of emotional reaction to $\mathrm{H}-\mathrm{KR}$ within the month following $\mathrm{H}-\mathrm{KR}$, peritraumatic emotional responses were measured with a checklist, Types of Peritraumatic Emotional Responses, which was originally developed for Ai and colleagues' (2005) 9/11 study. We modified instructions to specify the context $(\mathrm{H}-\mathrm{KR})$ that evoked such emotional reactions. Using a five-point scale $(1=$ not at all, $5=$ a great deal), respondents indicated the extent to which they experienced the 12 types of emotional reactions. The first five items were summed as negative emotional responses $(\alpha=.82, M=12.27, S D=4.03)$, while the remaining seven items constituted positive emotional responses $(\alpha=.83, M=23.69, S D=4.05)$.

\section{Demographics}

Race and gender were dichotomized $(0=$ nonwhite, $1=$ white; $0=$ male, $1=$ female $)$. Religious belief was measured using a checklist of 15 items, including "other" and "no preference" choices.

\section{Analytic Strategy}

Data were entered into a database using a double-entry system to ensure quality. No missing values were replaced. First, we compared faith factors and major constructs for minority and white respondents at the univariate level, using chi-square and $t$-tests. Then, the normality of these data at both univariate and multivariate levels was examined to meet assumptions of the SEM estimation. Zero-order correlations were then performed to examine bivariate relations of constructs in the theoretical model.

Next, the hypothetical model using SEM was estimated, as shown in Model 1 (Figure 1). Mean scores of all scaled indicators were used. There was one latent factor, positive attitudes, with two indicators (hope and optimism). We then evaluated the hypothetical model with the maximum-likelihood estimator and a robust tool, Mplus software version 3. In Mplus modeling, all structural paths among latent constructs in hypothetical models are simultaneously estimated, while path coefficients are estimated in the presence of residual measurement errors in the equations. In this case, all paths were tested and all direct and indirect effects of the antecedent 
Table 2: Belief patterns and higher powers

\begin{tabular}{|c|c|c|c|}
\hline Religious affiliation & & $\begin{array}{c}\text { Minority } \\
N(\%)\end{array}$ & $\begin{array}{l}\text { White } \\
N(\%)\end{array}$ \\
\hline Agnostic & & $\begin{array}{c}1 \\
(.3 \%)\end{array}$ & $\begin{array}{c}11 \\
(5.4 \%)\end{array}$ \\
\hline Atheist & & $\begin{array}{c}0 \\
(0 \%)\end{array}$ & $\begin{array}{c}6 \\
(3.0 \%)\end{array}$ \\
\hline Buddhist & & $\begin{array}{c}2 \\
(.6 \%)\end{array}$ & $\begin{array}{c}0 \\
(0 \%)\end{array}$ \\
\hline Hindu & & $\begin{array}{c}2 \\
(.6 \%)\end{array}$ & $\begin{array}{c}0 \\
(0 \%)\end{array}$ \\
\hline Jewish & & $\begin{array}{c}1 \\
(.3 \%)\end{array}$ & $\begin{array}{c}4 \\
(2.0 \%)\end{array}$ \\
\hline Eastern Orthodox & & $\begin{array}{c}2 \\
(.6 \%)\end{array}$ & $\begin{array}{c}2 \\
(1.0 \%)\end{array}$ \\
\hline Protestant & & $\begin{array}{c}238 \\
(70.2 \%)\end{array}$ & $\begin{array}{c}94 \\
(46.3 \%)\end{array}$ \\
\hline Native American religions/spirituality & & $\begin{array}{c}4 \\
(1.2 \%)\end{array}$ & $\begin{array}{c}0 \\
(0 \%)\end{array}$ \\
\hline Roman Catholic & & $\begin{array}{c}32 \\
(9.4 \%)\end{array}$ & $\begin{array}{c}49 \\
(24.1 \%)\end{array}$ \\
\hline No preference & & $\begin{array}{c}17 \\
(5.0 \%)\end{array}$ & $\begin{array}{c}17 \\
(8.4 \%)\end{array}$ \\
\hline Other & & $\begin{array}{c}40 \\
(11.8 \%)\end{array}$ & $\begin{array}{c}19 \\
(9.4 \%)\end{array}$ \\
\hline Spiritual connections & $N(\%)$ & $N(\%)$ & $p$-value $\left(\chi^{2}\right)$ \\
\hline God & $\begin{array}{c}325 \\
(95.9 \%)\end{array}$ & $\begin{array}{c}171 \\
(86.4 \%)\end{array}$ & $<.001$ \\
\hline Jesus Christ & $\begin{array}{c}280 \\
(82.6 \%)\end{array}$ & $\begin{array}{c}137 \\
(68.8 \%)\end{array}$ & $<.001$ \\
\hline An angel & $\begin{array}{c}87 \\
(25.6 \%)\end{array}$ & $\begin{array}{c}31 \\
(15.6 \%)\end{array}$ & $<.050$ \\
\hline Virgin Mary & $\begin{array}{c}60 \\
(17.6 \%)\end{array}$ & $\begin{array}{c}40 \\
(21.6 \%)\end{array}$ & $\mathrm{ns}$ \\
\hline A saint & $\begin{array}{c}43 \\
(12.6 \%)\end{array}$ & $\begin{array}{c}28 \\
(14.1 \%)\end{array}$ & ns \\
\hline My ancestor & $\begin{array}{c}45 \\
(13.2 \%)\end{array}$ & $\begin{array}{c}18 \\
(9.0 \%)\end{array}$ & ns \\
\hline The mother earth & $\begin{array}{c}31 \\
(9.1 \%)\end{array}$ & $\begin{array}{c}18 \\
(9.0 \%)\end{array}$ & ns \\
\hline The energy field & $\begin{array}{c}7 \\
(2.1 \%)\end{array}$ & $\begin{array}{c}15 \\
(7.5 \%)\end{array}$ & $<.010$ \\
\hline The cosmos & $\begin{array}{c}5 \\
(1.5 \%)\end{array}$ & $\begin{array}{c}15 \\
(7.5 \%)\end{array}$ & $=.001$ \\
\hline Other spiritual force & $\begin{array}{c}10 \\
(2.9 \%)\end{array}$ & $\begin{array}{c}9 \\
(4.5 \%)\end{array}$ & ns \\
\hline Buddha & $\begin{array}{c}6 \\
(1.8 \%)\end{array}$ & $\begin{array}{c}4 \\
(2.0 \%)\end{array}$ & ns \\
\hline Muhammad & $\begin{array}{c}7 \\
(2.1 \%)\end{array}$ & $\begin{array}{c}1 \\
(.5 \%)\end{array}$ & ns \\
\hline None & $\begin{array}{c}5 \\
(8.9 \%)\end{array}$ & $\begin{array}{c}8 \\
(9.6 \%)\end{array}$ & ns \\
\hline
\end{tabular}


Figure 2

Final solutions with standardized coefficients (Model 2)

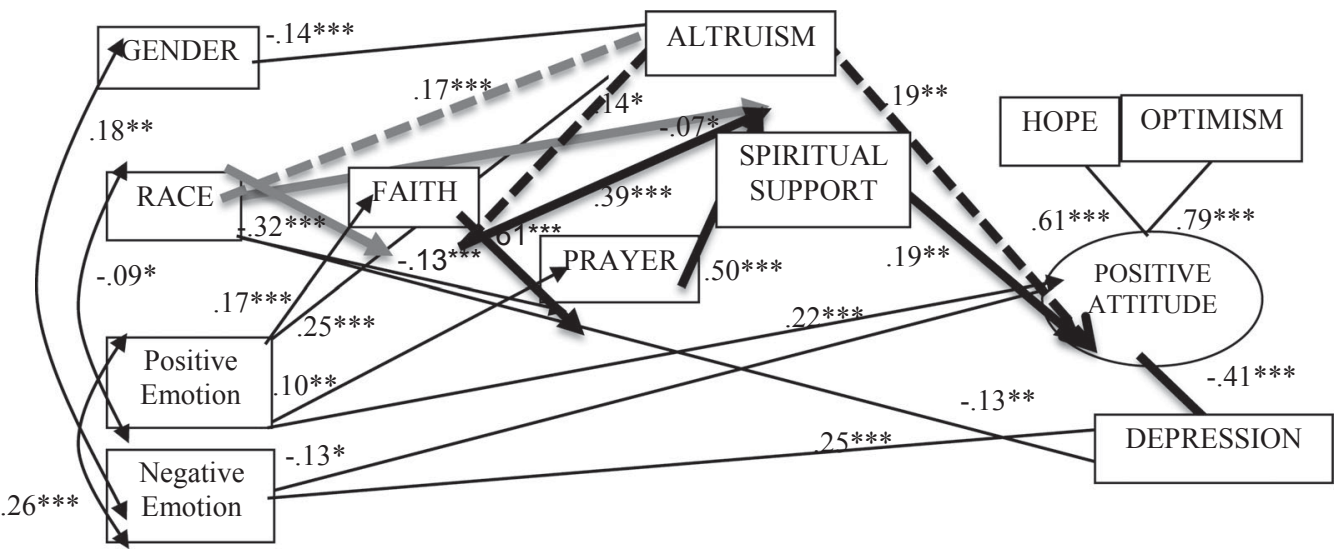

Note $: N=541 ; \chi^{2}(23,527)=42.242 ; \mathrm{CFI}=.987 ; \mathrm{TLI}=.972 ; \mathrm{RMSEA}=.040(.020$ to .059$) ; \mathrm{SRSM}=.027$.

variables on depression and positive attitudes were computed (MacKinnon et al. 2002; Shrout and Bolger 2002). However, the final model (Model 2, Figure 2) displays only statistically significant standardized path coefficients $(p<.05)$.

Following Bollen and Long's (1993) recommendation, several goodness-of-fit indices were used in addition to the chi-square statistic that is sensitive to both the assumption of normality and sample size. These included the standardized root mean square residual (SMSR) index and the residual mean squared error of approximation (RMSEA) with values around .05 (the lower bound of the 90 percent confidence interval under .05) indicating adequate fit (Browne and Cudeck 1993). The comparative fit index (CFI) (Bentler 1990) was also employed with the recommended adequate fit of values around .95 or greater (Hu and Bentler 1999). Because missing values were very rare, we did not modify any cell for all measures.

\section{RESUlts}

There were fewer respondents who checked "Jesus" as the higher power than those claiming "Christian" as their belief. Those who checked "God" (over 90 percent) were more than the sum of all monotheist and polytheist beliefs. The number who checked "my ancestor" was much higher than that of believers in "Native American spirituality." No one checked "Muslim" or "Baha'i" on the question on belief, but eight persons ( $>1$ percent) checked "Muhammad" as their spiritual higher power. Over 92 percent of all respondents used prayer in the aftermath of $\mathrm{H}-\mathrm{KR}$ (see Table 1). Prayers specific to H-KR were primarily performed for evacuees, for victims' families, and for persons in one's own social circle (80-87 percent), followed by prayer for (a) volunteers, (b) personal strength for coping and helping, (c) God's will to be done, (d) the best thing to happen, and (e) the souls of victims (59-74 percent). Other prayers focused on the prevention of future disasters (48 percent) and on a combination of miscellaneous forms not on the list (33 percent).

Table 2 presents further cross-cultural differences between minority and white respondents on faith factors and major constructs in the final model for the whole group. For three faith factors, results of chi-square tests indicated that rates of Protestantism, other religions, Native American faiths, and Buddhism/Hinduism were higher among minority than white respondents. White respondents were more likely to report their faith as Roman Catholicism, no preference, agnosticism, atheism, Judaism, Orthodox, and Unitarianism. Next, respondents specified the spiritual 
Table 3: Correlations of measured concepts in the model

\begin{tabular}{|c|c|c|c|c|c|c|c|c|c|c|}
\hline & 1 & 2 & 3 & 4 & 5 & 6 & 7 & 8 & 9 & 10 \\
\hline 1. Faith & - & & & & & & & & & \\
\hline 2. Prayer & $.672^{* *}$ & - & & & & & & & & \\
\hline 3. Spiritual support & $.747^{* *}$ & $.784^{* *}$ & - & & & & & & & \\
\hline 4. Altruism & $.149^{* *}$ & .111 & $.124^{*}$ & - & & & & & & \\
\hline 5. Optimism & $.163^{* *}$ & $.169^{* *}$ & $.217^{* *}$ & $.172^{* *}$ & - & & & & & \\
\hline 6. Hope & $.102^{* *}$ & $.120^{*}$ & $.190^{* *}$ & $.269^{* *}$ & $.482^{* *}$ & - & & & & \\
\hline 7. Depression & -.020 & .002 & .000 & -.097 & $-.362^{* *}$ & $-.215^{* *}$ & - & & & \\
\hline 8. Race & $-.341^{* *}$ & $-.349^{* *}$ & $-.372^{* *}$ & $.094^{*}$ & -.051 & -.013 & $-.099^{*}$ & - & & \\
\hline 9. Gender & .060 & $.082^{*}$ & $.086^{*}$ & $-.120^{* *}$ & .014 & $-.085^{*}$ & .064 & -.049 & - & \\
\hline 10. Positive emotion & $.198^{* *}$ & $.230^{* *}$ & $.234^{* *}$ & $.257^{* *}$ & $.213^{* *}$ & $.200^{* *}$ & -.049 & $-.093^{*}$ & .058 & - \\
\hline 11. Negative emotion & -.035 & -.013 & -.004 & .023 & .078 & .020 & $.276^{* *}$ & .009 & $.176^{* *}$ & $.258^{* *}$ \\
\hline
\end{tabular}

Notes: $N=527 ; * p<.05 ; * *<<.01$.

higher powers in their faiths in their answers to one item undersubsuming the Spiritual Support Scale. As shown in Table 2, minority respondents experienced higher spiritual connections with God, Jesus Christ, and angels, whereas white respondents were more likely to report connections with the energy field, the cosmos, and other spiritual forces. There were no differences between the two subgroups in rates of spiritual connections with the Virgin Mary, saints, ancestors, mother earth, Buddha, Muhammad, or "none." Finally, minorities reported higher levels of H-KR-related prayer for all specified targets than their white counterparts in answers to one item subsumed under the Using Prayer for Coping Scale. For major constructs in the hypothetical model, there were no statistical differences on measures of optimism, hope, or peritraumatic negative emotions between minority and white respondents, despite slightly higher levels of depression scores in the former subgroup than in the latter. Overall, the minority subgroup presented significantly higher levels of faith strengths, using prayer for coping, and perceived spiritual support, as well as of peritraumatic positive emotions, whereas the latter group reported a higher level of altruism.

\section{Normality Analysis and Bivariate Correlations}

The kurtosis and skewness of factor distributions in Model 1 (Figure 1) all fell within acceptable ranges concerning univariate normality analyses. The Mahalanobis distance test for multivariate normality analyses identified a few outliers among the 554 cases. After listwise deletion, the final model was tested in a sample of 527. No violation of normal distribution was shown for any indicators after deletion of outliers. Thus, raw scores were used in estimating the hypothetical model (Figure 1, Model 1). The zero-order correlations of constructs estimated in Model 1 are presented in Table 3. The correlation between paired indicators of one latent factor, positive attitudes, was of a moderately high magnitude (optimism and hope [.48, $p<.001]$ ). Signs of significant coefficients were chiefly consistent with expected directions.

As seen in Table 3, depression was negatively correlated with both optimism and hope and with altruism at a modest magnitude. Perceived spiritual support and altruism were positively correlated. Prayer was correlated strongly with spiritual support and moderately correlated with optimism, hope, and altruism. Faith strength was correlated highly with prayer and spiritual support and moderately so with optimism, hope, and altruism. Further, female gender was correlated with spiritual support, whereas male gender was correlated with hope and altruism, mostly at moderate magnitudes. White identity was moderately correlated with altruism and black identity was linked with faith factors, all at moderately high magnitudes and with both positive emotions and depression at a very moderate level. Positive emotions were correlated with all character strengths, whereas negative emotions were linked with depression and female gender. The two types were also positively correlated with each other. 
Table 4: Total indirect effects of antecedent constructs concerning depression and positive attitudes

\begin{tabular}{lccccc}
\hline & \multicolumn{2}{c}{ Depression } & & \multicolumn{2}{c}{ Positive Attitude } \\
\cline { 2 - 3 } & Estimates & $Z$ & & Estimates & $Z$ \\
\hline Faith strength & -.055 & -3.925 & & .122 & 4.474 \\
Prayer coping & -.030 & -3.422 & & .066 & 3.769 \\
Spiritual support & -.063 & -3.509 & & $-{ }^{1}$ & - \\
Altruism & -.053 & -3.459 & & $-{ }^{1}$ & - \\
White & $-.020^{1}$ & -2.003 & & -.045 & -2.067 \\
Female & - & - & & - & - \\
Positive emotions & $-.119^{1}$ & -4.562 & & $.073^{1}$ & 4.408 \\
Negative emotions & $.035^{1}$ & 2.367 & & $-{ }^{1}$ & - \\
\hline
\end{tabular}

Notes: ${ }^{1}$ Total effects differ from indirect effects, which are presented in the text or obvious in the final model; - means null or nonsignificant indirect effect; $N=527$.

\section{Pathways to Levels of Depressive Symptoms}

The initial estimation of Model 1 with Mplus 3 resulted in a satisfactory fit to the data; however, the modification index suggested that the addition of one theoretically plausible path (i.e., from race identity to depression) would make the model fit even more adequately. Accordingly, we added only this path to the original model in Figure 1 without deleting any insignificant paths. After this addition, no other direct link among constructs was recommended. The final solution (Figure 2, Model 2), including standardized coefficients of all significant paths only, indicated that one latent factor, positive attitude, was measured adequately by its respective indicators with high factor loading. Unlike in Model 1, the three insignificant paths (directed from gender to prayer and faith and from spiritual support to altruism) were not shown in Model 2. The five indices all indicated that the model fit the data adequately. The chi-square value was within the acceptable range (chi-square $(23, N=527)=42.242)$. The CFI (.987) and Tucker-Lewis Index (.972) both exceeded the benchmark criterion of .95. RMSEA (.040, 90 percent CI .020 to .059) and SRMR (.027) were within the range of good fit. Squared multiple correlations suggested that the model accounted for 25 percent of the variance in emotional distress and over one-sixth (16.8 percent) of the variance in positive attitudes.

The significant paths in Model 2 were generally consistent with those in the hypothetical Model 1, but not all significant correlations in the zero-order analysis remained significant paths here. Some of these paths are worth noting. As anticipated, all effects of two main pathways, spiritual support and altruism, on depression were indirect, mediated through positive attitudes. While faith contributed to both pathways, prayer was directly linked only with spiritual support. However, spiritual support and altruism were unrelated. White identity was positively and directly linked with altruism, whereas black identity was indirectly associated with both pathways, mediated through faith factors, with an additional effect on altruism through prayer and spiritual support. Unexpectedly, gender had no effect on any faith factor, although its direct link with altruism indicated a strong male influence. All of these paths manifested while adjusting for impacts of peritraumatic emotional responses. In anticipated directions, positive emotion affected faith, prayer, and positive attitudes, but not depression, whereas negative emotion influenced only positive attitudes and depression, in opposite directions.

Table 4 summarizes completely standardized indirect effects of all antecedent variables on depression and positive attitudes, in which all estimates are significant. Most total effects of these constructs in Model 2 are equivalent with indirect effects in Table 4, unless otherwise noted or obvious in the final model (Model 2). As noted, altruism, spiritual support, prayer 
coping, and faith all had desirable indirect effects on lower rates of depression. Prayer and faith also had similar indirect effects on positive attitudes through spiritual support. Gender was associated with neither depression nor positive attitudes. Specific indirect effects of all genderrelated links indicated that male gender, mediated through the altruism pathway, might have been counterbalanced by a summed potential effect of female gender mediated through other faith-related pathways. Because none of the latter paths had a significant effect, they were not shown in Model 2.

In contrast, race effects manifested in an interesting and complex pattern. The total indirect effect is positively related to nonwhite race with reduced depressive symptoms (estimate, .020), mediated through its links with both pathways showing deep connections. Yet, the total effect showed the link between nonwhite race and depression, accounting for its direct effect on symptomatology. Because of the counteracting indirect effect of nonwhite race through strength characters, the magnitude of its total effect on depression (estimate, -.118 ) was lower than that of its direct effect (estimate, -.139). In opposite directions, positive and negative peritraumatic responses were also indirectly associated with depression, mediated through attitude indicators. Positive emotion also had additional positive indirect effects on positive attitudes, mediated through its direct and indirect links with the altruism pathway and various indirect links with the spiritual support pathway.

\section{Discussion}

Bonanno (2004) observes that trauma research has focused primarily on predictors of stress reactions rather than on predictors of resilience. Integrating a positive and strengths-based perspective into trauma research may foster movement from a variable-focused to a more person-focused orientation to intervention (Masten 2001). The current study estimated pathways of perceived spiritual support and altruism, indicating the character strengths spirituality and kindness, leading to low symptom levels of depression after H-KR among minority and white respondents who had been volunteered in disaster relief actions. The primary findings in the final model are generally consistent with our expectations (Model 2): volunteers who reported greater experiences of deep connections held greater hope and optimism, which in turn predicted resilience in the aftermath of collective trauma. The spirituality pathway replicates the evidence from 9/11 models (Ai et al. 2005; Ai, Tice et al. 2011), while the kindness pathway is more specific to the circumstances faced by $\mathrm{H}-\mathrm{KR}$ volunteers. Optimistic expectations were spawned by deep connections in the two-dimensional reality, in line with psychological literature on the benefits of reaching out to other people (Monroe 1996) and the sacred (Pargament 1997). Our model is relevant to the field of positive psychology, which considers character strengths to be self-transcendent and transformative in persons' lives (Peterson and Seligman 2004) and to the field of psychology of religion, in which spirituality, centered on the yearning for a connection with the sacred, is seen a coping resource that protects well-being (Pargament 1997).

Despite commonalities shared between minority and white respondents in both parallel spiritual and secular pathways, results from univariate and SEM analyses (i.e., signs of certain paths from several exogenous variables to the two character strength pathways) present different cultural roots between subgroups. In univariate results, minority respondents scored higher on connections with mainstream-religion-related higher powers (e.g., Christianity), whereas white respondents scored higher on New-Age-belief-related spiritual forces (e.g., the energy field), despite no differences on other conceptions of higher powers (e.g., ancestors). Minority respondents also reported greater faith strengths, more use of prayer for coping, and higher perceived spiritual support, whereas white respondents reported greater altruism. Further, in the final SEM results, the path from minority respondents to the spiritual support pathway suggests their stronger reliance on faith than is the case among white respondents (Lawson and Thomas 2007; Taylor, 
Chatters, and Levin 2004). On the other hand, paths from white identity and male gender to the altruism pathway reflect a secular culture tracing back to modern Western European roots (Dixon 2005) and stronger reliance on their secular mental resources. Overall, our findings lend support to assumed core experiences among minority and white respondents, with character strengths in deep connections paving the way to postdisaster optimism and resilience, even though cultural roots may nourish character strengths differently.

Two unique findings are noteworthy. The first concerns commonality between minority and white respondents. Substantively different concepts in meaningful connections (perceived spiritual support and altruism) appeared to bear nearly identical effects on optimistic expectations, which in turn explained the influence of character strengths on resilience. Yet, they generally operate in two different dimensions of perceived realities (physical vs. nonphysical) and at two levels of human relations (to the sacred vs. to other living beings) (Monroe 1996; Pargament 1997). Those who perceive spiritual support are likely to be beneficiaries of perceived transcendent powers in their beliefs, whereas altruists provide benefits to fellow humans. The recipients perceiving support in spirituality may not be asked for self-sacrifice as a condition of gaining the love of a benevolent higher power, whereas altruists would demonstrate kindness in actions to buoy the hope of others, even at their own expense. In light of the virtue transcendence, pursuit of spiritual support is one way of seeking meaningful relations in coping through the sacred in the context of faiths (Pargament 1997). On the other hand, in light of the virtue humanity, altruism is one way of engaging in meaningful actions through interpersonal contact (Frankl 1959). In spite of the underlying worldview differences, religious and secular deep connections appear to be equally motivating. Lepore and Evans (1996) underscore the significance of resources, be they social (e.g., social support), mental (e.g., hope, optimism), or spiritual (e.g., spiritual support), for coping.

Evidence has shown that optimistic expectations may explain the protective effect of religious involvement in daily coping and in adversity (Ai et al. 2005; Idler and Kasl 1997a, 1997b; Krause 2002). Structural equation models of other populations have indicated that hope and perceived social support may underlie the desirable spiritual coping effect on clinical outcomes ( $\mathrm{Ai}$ et al. 2005, 2007). Whereas the spirituality-positivity pathway may be explained by the resource mechanism (Lepore and Evans 1996), the altruism-positivity pathway may not be interpretable in the same way, given the risk-taking actions it naturally entails (e.g., actions at risk of sacrificing one's own life may end any personal hope). Rather, it is the power of the virtue humanity in humans' need for deep connection with others that enabled volunteers to prevail in the face of collective trauma. According to Vaillant (2000), altruism, an adaptive mental mechanism that transforms conflict, involves gaining a positive outcome from giving what altruists would themselves like to receive in the future. Altruists could experience satisfaction in their meaningful unselfish actions that may only benefit recipients, built on their communion-oriented worldview (Monroe 1996). An altruist's hope is not for the future of the self only, but for that of others in the world at large, which can be especially meaningful in the context of disasters that create significant community needs. The same pattern was shown after the collective trauma of $9 / 11$, which evoked not the need for intimacy indicating simple relatedness, but on a much deeper level, New Yorkers' desire to care for others (Woike and Matic 2004).

The sense of profound connection was clearly revealed both in volunteers' altruistic actions (Plummer et al. 2008) and in their use of prayer for coping with the devastation of H-KR. The most frequently reported categories of prayer revealed deep concern for others, including evacuees and strangers who were victims, as well as their families. Through their use of prayer for coping, these volunteers sustained intimate contact with the transcending sacred in their respective faiths for coping strength, thereby following in the footsteps of altruists who historically have been immortalized in many cultural legacies (Monroe 1996). Indeed, research on resilience should move beyond stress factors, personality characteristics, and psychopathology to include human strengths, such as faith factors and meaningful connections in different dimensions of 
life, shaping or shaking fundamental worldviews (Ai, Tice, and Kelsey 2009; Peterson and Seligman 2004). As noted in our univariate analyses, minority respondents reported higher levels of prayer targeting others. Our findings echo the only qualitative study documenting AfricanAmerican faith and spiritual support in the aftermath of H-KR (Lawson and Thomas 2007). In this study, elevated resilience and well-being among African Americans were tied to prayer, religious reading, devotionals, and providing assistance to others. Our study expands on the observations made by Lawson and Thomas (2007) with a SEM analysis that explains the role of spiritual coping and perceived support in the resilience of these young volunteers. More importantly, it also showed that minority participants' reliance on their spiritual powers was not merely for their own well-being but for that of others as well; in particular, their faith factors bolstered altruism.

Our second unique finding has to do with cultural influences. Altruism in minority and white respondents presents with different attributes. The stronger link between altruism and white race, a subgroup that was less religious, does suggest that the role of resilience may not only be rooted in religious faith, but also in altruism. The latter can be seen as an indicator of a secular human strength that represents deep human interconnectedness, as does spirituality. The exact explanations for higher levels of altruism among white respondents remain obscure. One possibility lies in great traumatization among minorities (e.g., posttraumatic stress symptoms, $\mathrm{H}-\mathrm{KR}$ related stressors, and recollection of prior traumas) following H-KR (Ai, Plummer, Kanno et al. 2011). Another possibility concerns the widely publicized image of severe victimization among New Orleans African Americans by H-KR that mobilized the sense of humanity and a secular spiritual strength in the form of altruism among whites. Still another possibility is that individualism is more relevant for whites than for nonwhites. Indeed, altruism could serve as a self-reassuring action in coping with the collective trauma, in this case $\mathrm{H}-\mathrm{KR}$, which could trigger the painful memory of racism running through the history of the Deep South. However, all these hypotheses are yet to be tested when more in-depth analyses can be done in the future.

Not surprisingly, in our final model minority race is associated with the faith-related spiritualsupport pathway to resilience, while white respondents are more secular. In addition, minority race is also correlated with peritraumatic positive emotions that are in turn related to greater use of prayer for coping. Further, the role of prayer in perceived spiritual support in the final model is stronger than that shown in Ai and colleagues' (2005) 9/11 model (.50 vs. .37), very likely due to larger proportions of African Americans and Judeo-Christians among respondents in the current study ( .82 percent vs. .57 percent). Although the suffering experienced by members of the African-American community of during H-KR was well documented, research on spirituality, coping, and resilience among them in the storms' aftermath lags behind (Lawson and Thomas 2007). The strong link between nonwhite race and the spirituality pathway in the current study is consistent with a substantial corpus of research confirming the importance of African-American faith in black people's coping and well-being (Constantine et al. 2002; Dilworth-Anderson et al. 2007; Tarakeshwar et al. 2005; Taylor, Chatters, and Levin 2004). Historically, African-American spirituality has been rooted in a communal struggle (Smith 1999). In the face of a grave threat to a particular component of the African-American community, a sense of deep spiritual connections once again is demonstrated in their coping with hope that enabled resilience in our findings. Perhaps most important, young people, as opposed to the elderly in the qualitative study (Lawson and Thomas 2007), undertook the altruistic actions in our study.

The severity of symptoms among minority respondents in the aftermath of H-KR was initially underestimated, as evidenced by the modification index that suggested the addition of a theoretical path from racial identity to depression in the final model. On the other hand, this addition helps to complete a loop between the unexpected link and the sets of deep-connection pathways (from faith factors to the outcome), demonstrating a moderating effect of faith-related pathways that mitigated the damaging effects of H-KR on African Americans' well-being. The levels of depressive symptoms among minority respondents could have been higher (estimates, -.118 vs. -.139 ) had there been no protection of their faith-based character strengths. Further, the 
literature has shown mixed findings concerning gender and altruism (Andreoni and Vesterlund 2001; Belansky and Boggiano 1994; Monk-Turner et al. 2002). In the present study, gender ultimately had no influence on outcomes, likely because of the stronger effect of female gender on faith-based coping, which canceled its weaker effect on altruism. Inconsistent with national data (Levin, Taylor, and Chatters 1994), there is no gender effect on faith links, perhaps suggesting generational differences between samples used in different studies. Alternatively, both men and women could have pursued spiritual support upon encountering the magnitude of the devastation wrought by $\mathrm{H}-\mathrm{KR}$.

The correlated positive and negative peritraumatic responses in the current study provide additional support for the coexistence of both distress and a positive mindset when struggling with other adverse life events (Ai, Tice et al. 2011). This latter conclusion remains preliminary until the present study is confirmed with replication in other samples, in other disaster-related contexts, or in a general population. Other limitations of this study ought to be acknowledged. As is the case with all observational studies, there is a possibility that additional unexamined confounding variables impacted the outcomes. A cross-sectional study does not permit causal inference. Nevertheless, the use of retrospective assessment to measure the immediate responses to $\mathrm{H}-\mathrm{KR}$ in the model can be informative and valuable. In other words, it may help establish a hypothetical time-related conceptual model that warrants confirmation in future longitudinal studies. Although advantageous for testing mediators in a theoretical model, SEM does not eliminate alternative models and also is more sensitive to statistical power, thus limiting the number of constructs that can be included.

The findings in a convenience sample may not be generalizable to other populations, including groups of victims who resided in locations further away from the flood in New Orleans during H-KR. Race may not be used to replace culture, but it may be seen as one indicator of culture. The gender distribution of the sample is primarily skewed toward female respondents, which nonetheless is representative of the student populations in these professional schools. Although every attempt was made to use neutral language when recruiting participants, we cannot exclude the possibility that respondents with particularly strong altruistic or faith-based motivations, or those who were especially resilient, were more likely to choose to participate in this H-KR study. Identity as a "professional helper" in and of itself may help buffer against psychological sequelae, although research consistently has shown a high prevalence of secondary trauma among mental health workers (Ai, Plummer, Kanno et al. 2011). It should be noted, however, that many participants were incoming students and joined the relief work before classes began for the fall semester. In any case, the lack of a nonvolunteer cohort for comparison purposes may be a valid criticism of the present study in that the findings might be due to a cohort effect in the context of a particular historical moment. Thus, the use of a comparison group in the future investigation would be beneficial to advance the knowledge base in this area of research.

Further, it is worth noting that resilience does not have a uniform definition and is a much broader concept than we capture in the present study. Projecting this concept as the absence of psychopathology does carry limitations because it is a latent concept with many different indicators. Future replication of our study should attempt to untangle these conceptual issues and incorporate a standardized measure for resilience. On a related note, we could not obtain data describing study participants' predisaster resilience and psychological problems prior to H-KR; nor could we compare their psychological traits and symptoms with those of nonvolunteer students. Moreover, the measure of altruism may not have fully captured the range of altruistic actions unique to the H-KR disaster. Risks involved in altruistic acts that were undertaken in the context of H-KR may also be presented in other contexts. That is, risk elements involved in altruistic behaviors may be context-specific and therefore merit further investigation when examining altruism and behaviors undertaken in different contexts. Finally, almost all the variables we used here are scales (see Figure 2, Model 2) and therefore should be considered as latent variables, which in turn renders their labeling essentially unspecified. 
In conclusion, the present study suggests that the human need for deep connections may inspire an optimistic orientation toward the future following a catastrophe, which may in turn strengthen resilience in the aftermath of a traumatic experience. However, when victims are confronted with collective trauma, pathways to optimal outcomes may (quite logically) vary by cultural roots. In an increasingly connected global environment, future studies of religion should help develop knowledge about human virtues in line with interdependence, human flourishing, and cooperative living, involving both spiritual and secular worldviews (Ai et al. 2009; Ai, Tice et al. 2011). Since the beginning of the new millennium, extraordinary collective trauma (9/11, Hurricanes Katrina and Rita, other significant weather events, major earthquakes, and mass shootings) has opened a window of opportunity for better understanding culture-embraced human strengths that lead to resilience. The effects of spirituality and kindness on resilience and its underlying mechanisms deserve more research attention, as do the far-reaching impacts of catastrophic events on many communities.

\section{REFERENCES}

Ai, Amy L., Daniel Hall, Kenneth Pargament, and Terrence N. Tice. 2012. Posttraumatic growth in patients who survived cardiac surgery: The predictive and mediating roles of faith-based factors. Journal of Behavioral Medicine 35(2):186-98.

Ai, Amy L. and Thomas R. McCormick. 2010. Increasing diversity of Americans' faiths alongside Baby Boomers' aging: Implications for health chaplains, intervention. Journal of Health Care Chaplaincy 16(1-2):24-41.

Ai, Amy L., Crystal Park, Bu Huang, Willard Rodgers, and Terrence N. Tice. 2007. Psychosocial mediation of religious coping: A prospective study of short-term psychological distress after cardiac surgery. Personality and Social Psychology Bulletin 33(6):867-82.

Ai, Amy L., Christopher Peterson, Stephen F. Bolling, and Harold Koenig. 2002. Private prayer and the optimism of middle-aged and older patients awaiting cardiac surgery. Gerontologist 42(1):70-81.

Ai, Amy L., Christopher Peterson, Terrence N. Tice, Stephen F. Bolling, and Harold Koenig. 2004. Faith-based and secular pathways to hope and optimism subconstructs in middle-aged and older cardiac patients. Journal of Health Psychology 9(3):435-50.

Ai, Amy L., Carol Plummer, Grace Hoe, Catherine Lemieux, Cassandra Simon, Patricia Taylor, and Valire Copeland. 2011. Racial identity related differential attributions of inadequate responses to Hurricane Katrina: A social-identity perspective. Race and Social Problems 3(1):13-24.

Ai, Amy L., Carol Plummer, Hanae Kanno, Grace Hoe, Hoa B. Appel, Cassandra E. Simon, and Clarence Spigner. 2011. Positive traits versus previous trauma: Racially different correlates with PTSD symptoms among Hurricane Katrina-Rita volunteers. Journal of Community Psychology 39(4):402-20.

Ai, Amy L., Terrence N. Tice, and Catherine L. Kelsey. 2009. Coping after 9/11: Deep interconnectedness and struggle in posttraumatic stress and growth. In The impact of 9/11 on psychology and education: The day that changed everything? edited by Matthew J. Morgan, pp. 115-38. New York: Palgrave Macmillan.

Ai, Amy L., Terrence N. Tice, Catherine Lemieux, and Bu Huang. 2011. Modeling the post-9/11 paradox in an existential domain: From deep connection and struggle to posttraumatic stress and growth. Archive for Psychology of Religion 33(2): 173-204.

Ai, Amy L., Terrence N. Tice, Christopher Peterson, and Bu Huang. 2005. Prayers, spiritual support, and positive attitudes in coping with the 9-11 national crisis. Journal of Personality 73(3):763-92.

Ai, Amy L., Paul Wink, Terrence N. Tice, Stephen F. Bolling, and Marshall Shearer. 2009. Prayer and reverence in naturalistic, aesthetic, and socio-moral contexts predicted fewer complications following coronary artery bypass. Journal of Behavioral Medicine 32(6):570-81.

Andreoni, James and Lisa Vesterlund. 2001. Which is the fairer sex? Gender differences in altruism. Quarterly Journal of Economics 116(1):293-312.

Belansky, Elaine S. and Ann K. Boggiano. 1994. Predicting helping behaviors: The role of gender and instrumental/expressive self-schemata. Sex Roles 30(9/10):647-62.

Bentler, Peter M. 1990. Comparative fit indexes in structural models. Psychological Bulletin 107(2):238-46.

Bollen, Kenneth and John S. Long. 1993. Testing structural equation models. Newbury Park, CA: Sage.

Bonanno, George A. 2004. Loss, trauma, and human resilience: Have we underestimated the human capacity to thrive after extremely aversive events? American Psychologist 59(1):20-28.

Browne, Michael W. and Robert Cudeck. 1993. Alternative ways of assessing model fit. In Testing structural equation models, edited by Kenneth Bollen and John S. Long, pp.136-62. Newbury Park, CA: Sage.

Buber, Martin. [1923] 1958. I and thou. New York: Charles Scribners' Sons. 
Chatters, Linda M., Jeffrey S. Levin, and Robert J. Taylor. 1992. Antecedents and dimensions of religious involvement among older black adults. Journal of Gerontology Series B: Social Sciences 47B(6):S269-78.

Chatters, Linda M. and Robert J. Taylor. 1989. Age differences in religious participation among black adults. Journal of Gerontology Series B: Social Sciences 44B(5):S183-89.

Comte, Auguste. [1851-1875] 2012. System of positive polity: Theory of the future of man. Charleston, SC: Nabu.

Constantine, Madonna G., Leo Wilton, Kathy A. Gainor, and Erica Lewis. 2002. Religious participation, spirituality, and coping among African American college students. Journal of College Student Development 43(5):605-13.

Dilthey, Wilhelm. 1991. Selected works volume I: Introduction to the human sciences, edited by Rudolf A. Makkreel and Frithjof Rodi. Princeton, NJ: Princeton University Press.

Dilworth-Anderson, Peggye, Gracie Boswell, and Monique D. Cohen. 2007. Spiritual and religious coping values and beliefs among African American caregivers: A qualitative study. Journal of Applied Gerontology 26(4):355-69.

Dixon, Thomas. 2005. The invention of altruism: Atheist religion, social science, and the ideal of service in Victorian Britain. In Science and beliefs: From natural philosophy to natural science, edited by David M. Knight and Matthew D. Eddy, pp. 195-212. Burlington, VT: Ashgate.

Emmons, Robert A. 2000. Is spirituality an intelligence? Motivation, cognition, and the psychology of ultimate concern. International Journal for the Psychology of Religion 10(1):3-26.

Frankl, Viktor E. 1959. Men's search for meaning. New York: Touchstone.

Grant, Colin. 2001. Altruism and Christian ethics. New York: Cambridge University Press.

$\mathrm{Hu}$, Li-tze and Peter Bentler. 1999. Cutoff criteria for fit indexes in covariance structure analysis: Conventional criteria versus new alternatives. Structure Equation Modeling 6(1):1-55.

Idler, Ellen L. and Stanislav V. Kasl. 1997a. Religion among disabled and nondisabled persons I: Cross-sectional patterns in health practices, social activities, and well-being. Journal of Gerontology, Series B: Social Sciences 52B(6):S294-S305.

. 1997b. Religion among disabled and nondisabled persons II: Attendance at religious services as a predictor of the course of disability. Journal of Gerontology, Series B: Social Sciences 52B(6):S306-16.

King, Daniel W., Linda A. King, David Foy, Terence M. Keane, and John A. Fairbank. 1999. Posttraumatic stress disorder in a national sample of male of female veterans: Risk factors, war-zone stressors, and resilience-recovery variables. Journal of Abnormal Psychology 108(1):164-70.

Kishon-Barash, Ronit, Elizabeth Midlarsky, and David R. Johnson. 1999. Altruism and the Vietnam War veteran: The relationship of helping to symptomatology. Journal of Traumatic Stress 12(4):655-62.

Koenig, Harold G. 1994. Religion and hope for the disabled elder. In Religion in aging and health: Theoretical foundations and methodological frontiers, edited by Jeffrey S. Levin, pp.18-51. Thousand Oaks, CA: Sage.

Krause, Neal. 2002. Church-based social support and health in old age: Exploring variations by race. Journal of Geronotology, Series B: Social Sciences 57B(4):S332-47.

Krueger, Robert F., Brian M. Hicks, and Matt McGue. 2001. Altruism and antisocial behavior: Independent tendencies, unique personality correlates, distinct etiology. Psychological Science 12(5):397-402.

Lawson, Erma J., and Cecilia Thomas. 2007. Wading in the waters: Spirituality and older black Katrina survivors. Journal of Health Care for the Poor and Underserved 18(2):341-54.

Lepore, Stephen J., and Gary W. Evans. 1996. Coping with multiple stressors in the environment. In Handbook of coping, edited by Moshe Zeidner and Norman S. Endler, pp. 350-77. New York: Wiley.

Lesniak, Karen T., William Rudman, Margaret B. Rector, and David Elkin. 2006. Psychological distress, stressful life events, and religiosity in younger African American adults. Mental Health, Religion and Culture 9(1):15-28.

Levin, Jeffrey S., Robert J. Taylor, and Linda M. Chatters. 1994. Race and gender differences in religion among older adults: Findings from four national surveys. Journal of Gerontology, Series B: Social Sciences 49B(3):S137-45.

MacKinnon, David P., Chondra M. Lockwood, Jeanne M. Hoffman, Stephen G. West, and Virgil Sheets. 2002. A comparison of methods to test mediation and other intervening variable effects. Psychological Methods 7(1):83104.

Marcel, Gabriel. 1995. The philosophy of existentialism. New York: Carol Publishing Group.

Masten, Ann. 2001. Ordinary magic: Resilience processes in development. American Psychologist 56(3):227-38.

Maton, Kenneth I. 1989. The stress-buffering role of spiritual support: Cross-sectional and prospective investigations. Journal for the Scientific Study of Religion 28(3):310-23.

McFarlane, Alexander and Rachel Yehuda. 1996. Resilience, vulnerability, and the course of posttraumatic reactions. In Traumatic stress, edited by Bessel A. van der Kolk, Alexander C. McFarlane, and Lars Weisaeth, pp.151-81. New York: Guilford.

Monk-Turner, Elizabeth, Victoria Blake, Fred Chniel, Sarah Forbes, Lisa Lensey, and Jason Madzuma. 2002. Helping hands: A study of altruistic behavior. Gender Issues 20(4):65-70.

Monroe, Kristen Renwick. 1996. The heart of altruism: Perception of a common humanity. Princeton, NJ: Princeton University Press.

Musick, Marc and John Wilson. 2003. Volunteering and depression: The role of psychological and social resources in different age groups. Social Science and Medicine 56(2):259-69. 
Pargament, Kenneth I. 1990. God help me (I): Toward a theoretical framework of coping for the psychology or religion. Research in the Social Scientific Study of Religion 2(1):195-224.

—. 1997. The psychology of religion and coping: Theory, research, practice. New York: Guilford.

Peterson, Christopher. 2000. The future of optimism. American Psychologist 55(1):44-55.

Peterson, Christopher and Martin E. P. Seligman. 2003. Character strengths before and after September 11. Psychological Science 14(4):381-84.

- 2004. Character strengths and virtues: A handbook and classification. New York: Oxford University Press.

Plummer, Carol, Amy L. Ai, Catherine Lemieux, Roslyn Richardson, Shabari Dey, Patricia Taylor, Susie Spence, and Hyun-Jun Kim. 2008. Volunteerism among social work students during Hurricanes Katrina and Rita: A report from the disaster area. Journal of Social Service Research 34(3):55-71.

Post, Stephen G. 2005. Altruism, happiness, and health: It's good to be good. International Journal of Behavioral Medicine 12(2):66-77.

Radloff, Lenore S. 1977. The CES-D scale: A self-report depression scale for research in the general population. Applied Psychological Measurement 1(3):385-401.

Rushton, Jean P., Roland D. Chrisjohn, and Geziena C. Fekken. 1981. The altruistic personality and the Self-Report Altruism Scale. Personality and Individual Differences 2(4):293-302.

Scheier, Michael F. and Charles S. Carver. 1985. Optimism, coping and health: Assessment and implications of generalized outcome expectancies. Health Psychology 4(3):219-47.

- 1987. Dispositional optimism and physical well-being: The influence of generalized outcome expectancies on health. Journal of Personality 55(2):169-210.

Schleiermacher, Friedrich. [1821] 1969. On religion: Addresses in response to its cultured critics, 3rd ed. Richmond, VA: John Knox Press.

Schwartz, Carolyn, Janice B. Meisenhelder, Yunsheng Ma, and George Reed. 2003. Altruistic social interest behaviors are associated with better mental health. Psychosomatic Medicine 65(5):778-85.

Seligman, Martin E. P., Tracy A. Steen, Nansook Park, and Christopher Peterson. 2005. Positive psychology progress: Empirical validation of interventions. American Psychologist 60(5):410-21.

Shrout, Patrick E. and Niall Bolger. 2002. Mediation in experimental and nonexperimental studies: New procedures and recommendations. Psychological Methods 7(4):422-45.

Smith, Archie. 1999. Reaching back and pushing forward: A perspective on African American spirituality. Theology Today 56(1):44-58.

Snyder, Charles R., Cheri Harris, John R. Anderson, Sharon A. Holleran, Lori M. Irving, Sandra T. Sigmon, Lauren Yoshinobu, June Gibb, Charyle Langelle, and Pat Harney. 1991. The will and the ways: Development and validation of an individual-differences measure of hope. Journal of Personality and Social Psychology 60(4):570-85.

Spilka, Bernard and Greg Schmidt. 1983. General attribution theory for the psychology of religion: The influence of event-character in attributions to God. Journal for the Scientific Study of Religion 22(4):326-39.

Spinoza, Benedict. 2000. Ethics. New York: Oxford University Press.

Sullivan, Gwynn B. and Martin J. Sullivan. 1997. Promoting wellness in cardiac rehabilitation: Exploring the role of altruism. Journal of Cardiovascular Nursing 11(3):43-52.

Tarakeshwar, Nalini, Nathan Hansen, Arlene Kochman, and Kathleen Sikkema. 2005. Gender, ethnicity and spiritual coping among bereaved HIV-positive individuals. Mental Health, Religion and Culture 8(2):109-25.

Taylor, Robert J., Linda M. Chatters, and Jeff Levin. 2004. Religion in the lives of African Americans: Social, psychological, and health perspectives. Thousand Oaks, CA: Sage.

Tugade, Michelle M., Barbara L. Fredrickson, and Lisa Feldman Barrett. 2004. Psychological resilience and positive emotional granularity: Examining the benefits of positive emotions on coping and health. Journal of Personality 72(6):1161-90.

Vaillant, George E. 2000. Adaptive mental mechanisms: Their role in a positive psychology. American Psychologist 55(1):89-98.

Vieten, Ulrike M. 2006. Out in the blue of Europe: Modernist cosmopolitan identity and the deterritorialization of belonging. Patterns of Prejudice 40(3):259-79.

Woike, Barbara A. and Dina Matic. 2004. Cognitive complexity in response to traumatic experiences. Journal of Personality 72(3):633-58. 